June 2006

\title{
The impact of classroom aggression on the development of aggressive behavior problems in children
}

Duane Thomas

University of Pennsylvania, duanet@gse.upenn.edu

Follow this and additional works at: https://repository.upenn.edu/gse_pubs

\section{Recommended Citation}

Thomas, D. (2006). The impact of classroom aggression on the development of aggressive behavior problems in children. Retrieved from https://repository.upenn.edu/gse_pubs/174

Copyright Cambridge University Press. Reprinted from Development and Psychopathology, Volume 18, Issue 2, June 2006, pages 471-487.

Publisher URL: http://dx.doi.org/10.1017/S0954579406060251

This paper is posted at ScholarlyCommons. https://repository.upenn.edu/gse_pubs/174

For more information, please contact repository@pobox.upenn.edu. 


\title{
The impact of classroom aggression on the development of aggressive behavior problems in children
}

\begin{abstract}
Prior research suggests that exposure to elementary classrooms characterized by high levels of student aggression may contribute to the development of child aggressive behavior problems. To explore this process in more detail, this study followed a longitudinal sample of 4,907 children and examined demographic factors associated with exposure to high-aggression classrooms, including school context factors (school size, student poverty levels, and rural vs. urban location) and child ethnicity (African American, European American). The developmental impact of different temporal patterns of exposure (e.g., primacy, recency, chronicity) to high-aggression classrooms was evaluated on child aggression. Analyses revealed that African American children attending large, urban schools that served socioeconomically disadvantaged students were more likely than other students to be exposed to highaggressive classroom contexts. Hierarchical regressions demonstrated cumulative effects for temporal exposure, whereby children with multiple years of exposure showed higher levels of aggressive behavior after 3 years than children with primacy, less recent, and less chronic exposure, controlling for initial levels of aggression. Implications are discussed for developmental research and preventive interventions.
\end{abstract}

\section{Comments}

Copyright Cambridge University Press. Reprinted from Development and Psychopathology, Volume 18, Issue 2, June 2006, pages 471-487.

Publisher URL: http://dx.doi.org/10.1017/S0954579406060251 
REGULAR ARTICLE

\title{
The impact of classroom aggression on the development of aggressive behavior problems in children
}

\author{
DUANE E. THOMAS,${ }^{a}$ KAREN L. BIERMAN,${ }^{b}$ AND THE CONDUCT \\ PROBLEMS PREVENTION RESEARCH GROUP \\ ${ }^{a}$ University of Pennsylvania; and ${ }^{b}$ Pennsylvania State University
}

\begin{abstract}
Prior research suggests that exposure to elementary classrooms characterized by high levels of student aggression may contribute to the development of child aggressive behavior problems. To explore this process in more detail, this study followed a longitudinal sample of 4,907 children and examined demographic factors associated with exposure to high-aggression classrooms, including school context factors (school size, student poverty levels, and rural vs. urban location) and child ethnicity (African American, European American). The developmental impact of different temporal patterns of exposure (e.g., primacy, recency, chronicity) to high-aggression classrooms was evaluated on child aggression. Analyses revealed that African American children attending large, urban schools that served socioeconomically disadvantaged students were more likely than other students to be exposed to high-aggressive classroom contexts. Hierarchical regressions demonstrated cumulative effects for temporal exposure, whereby children with multiple years of exposure showed higher levels of aggressive behavior after 3 years than children with primacy, less recent, and less chronic exposure, controlling for initial levels of aggression. Implications are discussed for developmental research and preventive interventions.
\end{abstract}

There is mounting evidence that school environments can contribute to the socialization and promotion of childhood aggressive behav-

Members of the Conduct Problems Prevention Research Group include Karen L. Bierman, Pennsylvania State University; John D. Coie, Duke University; Kenneth A. Dodge, Duke University; E. Michael Foster, Pennsylvania State University; Mark T. Greenberg, Pennsylvania State University; John E. Lochman, University of Alabama; Robert J. McMahon, University of Washington; and Ellen E. Pinderhughes, Tufts University. This research was supported by the National Institute of Mental Health Grants R18MH48083, R18MH50951, R18MH50952, and R18MH50953. The Center for Substance Abuse Prevention, Department of Education, and the National Institute for Drug Abuse also provided support for FAST Track through a memorandum of support with the NIMH. Support has also come from the Department of Education grant S184430002, NIMH Grants K05MH00797 and K05MH01027, and a research grant from the Harry Frank Guggenheim Foundation. Appreciation is expressed to the parents, teachers, students, and school district personnel who supported this research in the Durham, NC, Nashville, TN, central Pennsylvania, and Seattle, WA areas. ior problems. Over the last two decades, structural features of schools, such as large size, economic disadvantage among the student body, and risky neighborhood conditions flanking school grounds, have been cited as variables associated with increased levels of student aggression (Colder, Mott, Flay, \& Levy, 2000; Howley, Strange, \& Bickel, 2000; Rutter, 1983). Less well studied are characteristics of classroom social contexts that may

The first author thanks Drs. Nicholas Ialongo and Shani Harris-Peterson, Johns Hopkins University, for their input on earlier drafts of this manuscript, as well as Drs. Chi-Ming Kam and Brenda Heinrichs, Pennsylvania State University, and Dr. Sharon Smith, National Institute on Alcohol Abuse and Alcoholism, for their statistical consultation with this project.

Address correspondence and reprint requests to: Duane E. Thomas, Applied Psychology and Human Development Division, Graduate School of Education, University of Pennsylvania, 3700 Walnut Street, Philadelphia, PA 19104. 
influence student behavior. Research suggests that exposure to grade school classrooms with many aggressive members may increase risk for persistent aggressive behavior problems (Barth, Dunlap, Dane, Lochman, \& Wells, 2004; Kellam, Ling, Merisca, Brown, \& Ialongo, 1998). However, important questions remain unanswered. Relations between structural features of the school context (e.g., size, student economic disadvantage, location) and prevalence of classroom-level aggression have not been examined, nor have the effects of these different aspects of school contexts been disentangled in terms of their effects on child aggression. Moreover, additional longitudinal research is needed to better understand the effects of exposure to high-aggressive classrooms and risky school contexts over time. The present study examined school and student demographics associated with exposure to classrooms characterized by high rates of student aggression and compared the impact of different patterns of temporal exposure on child aggressive behavioral outcomes.

\section{Negative Impact of High-Aggression Classrooms}

A focus on classroom influences is warranted by prior studies that demonstrate links between exposure to first-grade classrooms with many aggressive peers and subsequent high rates of aggressive behavior problems among students transitioning to middle school (Kellam et al., 1998; Perry \& Weinstein, 1998). Significant concerns have been raised about the iatrogenic effects of peer contagion in groups that contain many aggressive children (Dishion, McCord, \& Poulin, 1999). Theoretically, three different mechanisms may contribute to the negative impact of exposure to groups (or classrooms) containing many aggressive members.

First, according to the person-group similarity model (Tversky, 1977), social norms are heavily influenced by the prevalence of behaviors within groups. Groups with high concentrations of aggressive members may create a social milieu that normalizes aggressive behaviors, making them socially acceptable and decreasing social pressures to inhibit ag- gression or use alternative conflict management strategies (Henry et al., 2000; Wright, Giammarino, \& Parad, 1986). Several researchers have documented increases in the peer acceptability of aggression in groups (Boivin, Dodge, \& Coie, 1995; Wright et al., 1986) and classrooms (Stormshak, Bierman, Brushi, Dodge, Coie, \& The Conduct Problems Prevention Research Group, 1999) that contain many aggressive members. Moreover, Henry et al. (2000) found increases in children's aggression over time in elementary school classrooms characterized by students with normative beliefs accepting aggression.

Second, "deviancy training" models, based upon social learning principles, suggest that aggressive children, when paired, tend to model, provoke, and reinforce antisocial behavior (Dishion et al. 1999). Asarnow (1983) found that dyads containing two aggressive partners (compared with mixed or nonaggressive dyads) tended to escalate in conflict situations, showing longer and more aggressive conflictual exchanges, oriented toward dominating rather than resolving their disagreements. Similarly, Dishion, Spracklen, Andrews, and Patterson (1996) observed the interpersonal exchanges of antisocial youth in dyads, and found elevated levels of rule-breaking talk and higher levels of positive reinforcement (e.g., laughing) in response to rule-breaking talk than in mixed or nondelinquent dyads. These studies suggest that grouping aggressive children together increases the rate of exposure to aggressive provocation and behavioral reinforcement for aggressive responding (Dishion et al., 1999).

Third, research also suggests that classrooms that contain many aggressive-disruptive students make it difficult for teachers to forge positive relationships with students and use effective behavior management strategies to maintain control of the classroom (Brophy, 1996; Hawkins, VonCleve, \& Catalano, 1991; Hughes, Cavell, \& Jackson, 1999). Under these circumstances, teachers often resort to coercive and punitive discipline practices that, ironically, serve to increase rather inhibit student defiance (Hamre \& Pianta, 2001). These three processes (social norms, deviancy training, and coercive teacher control strategies) may all 
occur in combination, contributing to the escalating impact of exposure to high-aggression classrooms on student aggressive behaviors.

\section{School Context, Student Demographics, and Exposure to High-Aggression Classrooms}

Certain school and student demographics may increase child risk for exposure to highaggression classrooms. Howley et al. (2000) reviewed several studies showing that large schools are more likely than small schools to contain a high proportion of acting-out students and greater behavior management difficulties in classrooms. Similarly, Stephenson and Smith (1989) found that the incidence of peer aggression increased as a function of school and classroom size and levels of socioeconomic disadvantage in the student body. In general, school poverty (operationalized in most studies as the percentage of students qualifying for free/reduced lunch) is positively correlated with rates of student aggression (Battistich, Solomon, Kim, Watson, \& Schaps, 1995; Colder et al., 2000).

Prior research has also shown that children living in neighborhoods characterized by socioeconomic disadvantage and high rates of violence are at increased risk for experiencing and utilizing aggressive behaviors in the school setting (Colder et al., 2000; DuRant, Pendergrast, \& Cadenhead, 1994; Guerra, Tolan, Eron, Huesmann, \& Van Acker, 1995). According to Guerra et al. (1995), children living in impoverished urban areas, who witness community violence, often adopt normative beliefs approving aggression as a means of coping with fear of peer victimization. Normative beliefs supporting the use of aggression, along with affiliation with aggressive peers (Miller-Johnson et al., 2003), may both contribute to elevated rates of externalizing behavior problems in the classroom among children living and, in some cases, attending schools in risky, violent neighborhoods.

It is important to note that not all children have an equal likelihood of being exposed to these school contextual variables. Ethnic minority children may be especially vulnerable due to the higher likelihood they face of at- tending large schools located in areas beset with economic deprivation (Howley et al., 2000). In addition, because of a number of social stratification variables, including economic disadvantage and discrimination (see Garcia Coll et al., 1996), African American children, in particular, are more likely than other children to live and attend schools in risky, inner-city neighborhoods, where the risk of victimization by peers is high and where aggressive behavior may be sanctioned by peers as an effective strategy for self-protection and interpersonal conflict resolution (DuRant et al., 1994; Hanish \& Guerra, 2000; MillerJohnson et al., 2003).

Other than a recent study by Barth and colleagues (2004), there has been no inquiry into the impact of exposure to high-aggression classrooms on student behavior in the context of other, related school context characteristics, such as school size, student economic disadvantage, and urban location. The extent to which these factors explain common versus unique variance in the development of children's aggressive behavior warrants study.

\section{Effects of Temporal Patterns of Exposure to High-Aggression Classrooms}

Although previous research suggests that exposure to aggressive classrooms promotes escalations in child aggression, an important but neglected question involves the impact of exposure that varies in terms of developmental timing and length. Developmental theory and research suggest that exposure to aggressive classrooms might have a stronger impact on child aggressive behavior when it occurs early in elementary school (primacy effect). However, heuristic evidence from alternative schools of thought suggests that the impact of aggressive classrooms on child behavior could be greatest when exposure occurs closer to the assessment of outcomes (recency effect), or when it occurs across multiple school years (chronicity effect).

\section{Primacy effects}

Guided by the life course/social field theory model (Kellam \& Rebok, 1992), Kellam et al. (1998) postulated that exposure to classrooms 
with many aggressive members at the point of school entry has a critical and lasting impact on that child's aggressive behavior at school, a primacy effect. They argue that, at school entry, children face new behavioral demands for school adaptation, including getting along with peers and teachers and following a broad range of classroom rules. Children's mastery of these task demands is considered critical for their development of multiple competencies (social, emotional, and cognitive) that are needed for their later behavioral adaptation and psychosocial well being, and children who are unable to successfully navigate early social environments in school get off to a worse start and continue to suffer from their experience as they progress through elementary school (Alexander, Entwisle, \& Dauber, 1993; Hamre \& Pianta, 2001; Perry \& Weinstein, 1998). Children may therefore be more susceptible to influence by peers at school entry than in later years, and those children who are placed in high-aggression classrooms and adapt aggressive responding in the school environment may place themselves into a socialization trajectory in which they are likely to sustain their aggressive peer affiliations and aggressive behaviors in later school years. In support of this model, Kellam et al. (1998) found that children assigned to first-grade classrooms characterized by high levels of aggressive, disruptive student behaviors showed more aggressive behaviors 5 years later (when they were in the sixth grade) than students initially assigned to low aggression firstgrade classrooms. The investigators concluded that a single exposure to classrooms with high levels of student aggression early on may trigger the development of aggressive behavior problems for children with a lasting impact across grade levels. However, the classroom contexts these students experienced during the intervening years were not examined in this study, making it unclear whether the impact of first-grade classroom exposure was affected by subsequent classroom experiences.

\section{Recency effects}

Developmental theory suggests that, even after exposure to a significant negative social- ization experience (in this case, exposure to high-aggression first-grade classrooms), subsequent experiences often mitigate or exacerbate children's risk for behavior maladjustment (Belsky \& MacKinnon, 1994). To the extent that child aggressive behavior is affected by the immediate interpersonal contingencies in the environment, proximal exposure to peer social norms accepting aggression, peer "deviancy training," and coercive teacher management may shape child aggressive outcomes more than distal classroom experiences (Barth et al., 2004).

Recent exposure to classrooms with many aggressive peers may also function as a stressor for children, contributing to heightened sensitivity to perceived threat and self-protective hostile reactivity (Coie \& Dodge, 1998). The recency of exposure to stressful events is often a critical factor in determining their impact on child behavioral adjustment (Dohrenwend \& Dohrenwend). For example, DeRosier, Kupersmidt, and Patterson (1994) found that recent experiences of peer rejection predicted elevated levels of aggressive behavior, whereas more distal peer rejection did not. Hence, from the perspective of social norm models, social learning theory, and stressful life event models, more recent exposure to high-aggression classrooms might have a greater impact on rates of child aggressive behavior than more distal exposure.

\section{Chronicity effects}

Social learning theory and stress models also predict that the effects of aggressive classroom exposure would accumulate over time, increasing with more chronic exposure. That is, to the extent that aggressive behavioral reactions become established in a child's repertoire via social learning contingencies (deviancy training), behavioral outcomes should show a linear relationship between the time and intensity of exposure to coercive teaching and peer deviancy training. Similarly, chronic stress models (Johnson, 1988) postulate that persistent experiences with stressful events, as opposed to transient exposure, results in more adverse behavior outcomes (DeRosier et al., 1994; Dohrenwend \& Dohrenwend, 
1984; Johnson, 1988). Within both of these frameworks, the impact of aggressive classroom contexts would increase with more years of repeated exposure to classrooms with high levels of student aggression. In fact, DeRosier and colleagues (1994) found chronic peer rejection, in addition to recent exposure, increased child aggressive responding.

Hence, the timing and duration of exposure may be important, yet no prior study has compared the effects of primary (first grade), recent, or chronic exposure to classrooms characterized by high rates of student aggression on the behavioral functioning of children.

\section{The Present Study}

In summary, previous research indicates that student aggressive behavior problems are associated with demographic features of school contexts (size, student economic disadvantage, urban location), as well as with classroom contexts, particularly mean levels of classroom aggression (Kellam et al., 1998). Research is needed to explore the overlap between school and classroom contexts associated with student aggression, and to determine whether exposure to classroom aggression may explain (or add to) the impact of large, poor, urban schools on child aggressive development. In addition, a longitudinal framework is needed to better understand the degree to which the timing of exposure to aggressive classrooms (primacy, recency) and the amount of exposure (chronicity) affect child outcomes. All in all, we know little about which students are most at risk for exposure to high-aggression classrooms or how patterns of exposure to highaggression classrooms (whether they involve a single early, single recent, or more chronic exposure) affect the child aggressive outcomes. The present study addressed these questions.

First, the present study examined the relationship between school contextual variables, child ethnicity, and classroom aggression. It was expected that school demographics (large size, urban location, high levels of student poverty) create a distal context associated with elevated levels of student aggression and a corresponding high proportion of classrooms containing many aggressive students. Given the documented associations between these school demographics and student demographics (e.g., ethnic minority status; Howley et al., 2000), it was hypothesized that African American students would be more likely than European American students to attend large, urban schools serving economically disadvantaged students, and correspondingly, would be more likely to be placed in classrooms with many aggressive students (Garcia Coll et al., 1996; Hanish \& Guerra, 2000). We anticipated that, in addition to the distal effects of the school demographics, the classroom context would have a proximal impact on behavioral socialization, such that, even after school demographics were considered, high-aggression classrooms would contribute to increased levels of student aggressive-disruptive behaviors.

Second, the present study compared the aggressive outcomes of students who experienced different patterns of exposure to high-aggression classrooms in Grades 1-3. Assessing child aggression at the end of the third grade, the study tested hypotheses regarding the impact of timing and length of exposure to high-aggression classrooms. Given past evidence supporting a priming effect of early exposure to aggressive classrooms on later levels of child aggression, it was hypothesized that children with exposure to high-aggression classrooms in Grade 1 only would be significantly more aggressive at the end of Grade 3 than those children with no exposure (primacy effect). Based on the recency model, it was expected that children exposed to highaggression classrooms during the Grade 3 year only would be significantly more aggressive at the end of the third grade than children with no exposure (recency effect). Moreover, it was anticipated that the number of years children were exposed to classrooms with high levels of student aggression would predict significantly higher levels of aggressiveness at the end of the third grade (chronicity effect).

Third, the study examined the concurrent effects of individual child characteristics, school contextual factors, and classroom behaviors on aggressive outcomes in children. The relations between these variables were examined across child ethnicity and the geographic area in which schools were located. 


\section{Methods}

\section{Participants}

This study was conducted as part of a larger longitudinal investigation of the development and prevention of conduct disorders (Fast Track Program; see Conduct Problems Prevention Research Group, 1992). Participants were 4,907 children who remained in one of the 27 schools assigned to the no-treatment control condition of the prevention trial from kindergarten to Grade 4. These were children in the "universal" rather than "selected" Fast Track sample, so they included all children attending control schools participating in Fast Track. The participants were drawn from four geographic sites that represented a wide cross section of the American population. Three of the sites were located in urban locations (Durham, NC, $N=944$; Nashville, TN, $N=937$; Seattle, WA, $N=839$ ), whereas the remaining site comprised three rural counties in central Pennsylvania $(N=2,187)$. At each of the urban sites, schools in economically disadvantaged and high crime areas were identified and invited to participate. At the rural site, the three participating school districts served regions with elevated levels of economic disadvantage and townships with populations under 10,000 .

In the original sample of children for whom first-grade classroom data were available, there were 7,435 children. To examine the impact of classroom aggression over time, this study could include only students with classroom data for Grades 1-3. Thirty-four percent of the eligible sample did not meet this criteria $(N=2,528)$, almost exclusively due to residential mobility. In addition, classroom-level data were not collected from self-contained special education classrooms, so children placed in those classrooms were not included in the analyses. The first-grade aggression scores of children who were and were not retained did not differ, $F(1,7434)=.176$, $p>.10$. However, a greater proportion of the children attending rural versus urban schools remained in a core school over the 3 years of study and were retained in the sample $(1,508$ of the original 1,986 rural children, $76 \%$, vs.
2,008 of the original 5,449 urban children, $37 \%), \chi^{2}(1)=891, p \leq .001$.

The final sample included 2,503 (51\%) boys and 2,404 (49\%) girls. The ethnic composition of the sample was 34.3\% African American $(n=1,602)$ and $65.7 \%$ European American $(n=3,305)$. It should be noted that fewer than $2 \%$ of this sample represented individuals of other ethnicities (e.g., Latino/Hispanic, Native American, Asian American), and these children were not included in the subsequent analyses. Ethnicity was disproportionately related to urban versus rural school locations. Of the 2,008 children living in urban settings, $58.4 \%$ were African American, whereas of the 1,508 of the children living in rural settings, fewer than $1 \%(n=14)$ were African American. The percentage of children receiving free or reduced lunch averaged $49 \%$ (ranging from $23 \%$ in the rural schools to $71 \%$ in the urban schools).

\section{Measures}

School context measures. The average number of children per grade level was used as the measure of school size. The percentage of students in an individual child's school who qualified for free or reduced lunch was used as the index of the overall poverty level of the school (hereafter referred to as school poverty). The use of this variable was based on the premise that the economic status of schools typically reflects the socioeconomic status of the families served (Guerra et al., 1995).

Ratings of child aggression. Levels of child aggressive-disruptive behavior were assessed using the Authority Acceptance Scale of the Teacher Observation of Classroom Adaptation-Revised (TOCA-R; WerthamerLarsson, Kellam \& Wheeler, 1991). The scale included 10 items describing disobedient and aggressive behavior problems (e.g., yells at others, fights, breaks rules). For each item, teachers rated each child using a 6-point Likert scale to describe the frequency of the problem behaviors over the past 3 weeks, ranging from 1 (almost never) to 6 (almost always). Total scale scores were averaged to represent each child's level of aggressive-disruptive be- 
havior at each time point (Grades 1-3) and to assess classroom levels of aggression (see below). This scale demonstrated substantial internal consistency $(\alpha=.95)$ in this sample.

Ratings of classroom aggression. Teacher ratings of child aggression were also used to calculate classroom environment scores of aggression for each child in Grades 1-3. To derive a classroom-level score at each time point, classroom averages (total number of behavior problems teachers rated for all students in a classroom divided by the number of students rated) were computed excluding each child's individual scale score. Previous research has shown this procedure to be an effective strategy for ensuring that a scaled score of aggression for each individual child is calculated independently of his or her classroomlevel aggression score, protecting against a potential confound between the two measures (see Barth et al., 2004). A median split of the average classroom scores of aggression was used at each grade level to identify high- versus low-aggression classrooms. The mean score for high-aggression classrooms was 1.61 , compared to the mean of 0.91 for the low-aggression classrooms. Hence, for the low-aggression classrooms, the average level of aggressive-disruptive behavior was between "almost never" and "rarely" based on the descriptive anchors of the TOCA-R. For the high-aggression classrooms, the average level of aggressive-disruptive behavior was between "rarely" and "sometimes." These rates represent the fact that, for the sample of children in the present study, those in highaggression classrooms were exposed to a majority of students who engaged chronically in a low to moderate rate of aggressivedisruptive behaviors, compared with children in the low-aggression classrooms that were exposed to a majority of students who did not engage in any aggressive-disruptive behaviors.

\section{Procedures}

Information on school size and poverty was obtained from school administrators. Teacher ratings of child aggressive behavior were col- lected in the spring of kindergarten through the third grade. At each assessment, a trained research assistant visited the school and, in a face to face interview with the teachers, administered the TOCA-R. Teachers received monetary compensation for their participation.

\section{Results}

\section{Demographics associated with exposure to high-aggression classrooms}

It was postulated that ethnic minority children attending large urban schools with high levels of poverty would be at increased risk for exposure to high-aggression classrooms. To explore this possibility, bivariate correlations were computed to assess relations among school size, school poverty, urban-rural context, child ethnicity, and levels of classroom aggression across Grades 1-3. As shown in Table 1, significant levels of association emerged between the school and student demographics studied, such that African American students, students attending urban schools, and those in schools serving more economically disadvantaged families were more likely to experience classrooms with high levels of pupil aggression during their first year in formal schooling. Frequency counts revealed that, whereas $26 \%$ of the children living in rural sites experienced high-aggression classrooms in Grade 1, more than twice as many $(60 \%)$ of the children living in urban sites entered high-aggression first-grade classrooms, $\chi^{2}$ $(1)=109.01, p<.001$. African American students who, for the most part, attended schools in urban settings, were twice as likely as European American students to enter highaggression classrooms in Grade 1 (68 vs. $34 \%), \chi^{2}(1)=213.96, p<.001$. Similar patterns of associations were found between the school and student demographics studied and levels of aggression in Grades 2 and 3.

Of particular interest in the study was the degree to which the school context variables (e.g., size, poverty, urban vs. rural location) were independent and cumulative predictors of risk for exposure to high-aggression classrooms, and whether child ethnicity increased this risk, once the effects of school context 
Table 1. Correlations between school and student demographics and levels of classroom aggression

\begin{tabular}{lcccccc}
\hline \hline & School Poverty & Rural/Urban & Ethnicity & Class 1 & Class 2 & Class 3 \\
\hline School size & $.12 * * *$ & $.12 * * *$ & $.10^{* * *}$ & $.07 * * *$ & $.12 * * *$ & $.09 * * *$ \\
School poverty & - & $.48 * * *$ & $.53 * * *$ & $.08 * * *$ & $.13 * * *$ & $.11 * * *$ \\
Rural/urban & & - & $.61 * * *$ & $.05 * * *$ & $.08^{* * *}$ & $.06 * * *$ \\
Ethnicity & & - & $.03 *$ & $.12 * * *$ & $.13 * * *$ \\
Class 1 & & & - & $.32 * * *$ & $.31 * * *$ \\
Class 2 & & & & $-38^{* * *}$ \\
Class 3 & & & & - \\
\hline \hline
\end{tabular}

Note: School poverty, percentage of students qualified for and/or receiving free/reduced lunch; rural/urban, rural versus urban location of schools; Class 1, mean classroom aggression levels in Grade 1; Class 2, mean classroom aggression levels in Grade 2; Class 3, mean classroom aggression levels in Grade 3.

$* p<.05$. $* * * p<.001$.

Table 2. Hierarchical regression analysis predicting number of years of exposure to high-aggression classrooms in Grades 1-3

\begin{tabular}{|c|c|c|c|c|c|}
\hline Predictors & $B$ & $S E B$ & $\beta$ & $R^{2}$ & $\Delta R^{2}$ \\
\hline Step 1 & & & & $.06 * * *$ & \\
\hline Constant & .868 & .079 & - & & \\
\hline School size & .007 & .001 & $.113 * * *$ & & \\
\hline School poverty & .014 & .001 & $.216 * * *$ & & \\
\hline Urban/rural context & .009 & .054 & .003 & & \\
\hline Step 2 & & & & $.07 * * *$ & $.01 * * *$ \\
\hline Constant & .969 & .082 & - & & \\
\hline School size & .007 & .001 & $.111 * * *$ & & \\
\hline School poverty & .012 & .001 & $.179 * * *$ & & \\
\hline Urban/rural context & .115 & .058 & $.039 *$ & & \\
\hline Ethnicity & .304 & .062 & $.097 * * *$ & & \\
\hline
\end{tabular}

$* p<.05 . * * * p<.001$.

were taken into account. To address these questions, a hierarchical multiple regression procedure was undertaken predicting the number of years children experienced aggressive classrooms across the first three grades (e.g., never, once, twice, or three times; see Table 2). School context factors (school size, school poverty, and urban/rural location) were entered first, and they explained $6 \%$ of the variance. School size and school poverty each made significant unique contributions to this prediction. Child ethnicity, which was added in the second step of the model, predicted an additional $1 \%$ of the variance in the number of years children were exposed to aggressive classrooms. The small, but significant variance added by ethnicity suggests that, even within the large, poor, urban schools, African American students in the sample (relative to European American students) were at increased risk for placement in aggressive school classrooms.

\section{Group comparisons of patterns of exposure to aggressive classrooms}

To test hypotheses regarding the impact of different temporal patterns of exposure, groups of children were identified according to the timing and number of years that they were exposed to high-aggression classrooms from the first to the third grade. Children were classified into one of five profiles of exposure: no exposure (never, $N=959$ ), first-grade exposure only ( primacy, $N=436$ ), third-grade ex- 
Table 3. Descriptive statistics on profiles of child exposure to high-aggression classrooms

\begin{tabular}{lccccc}
\hline \hline & \multicolumn{5}{c}{ Profiles $(N=4,032)$} \\
\cline { 2 - 6 } & $\begin{array}{c}\text { Never } \\
(n=959)\end{array}$ & $\begin{array}{c}\text { Primacy } \\
(n=436)\end{array}$ & $\begin{array}{c}\text { Recency } \\
(n=469)\end{array}$ & $\begin{array}{c}\text { Chronicity } \\
(n=1,267)\end{array}$ & $\begin{array}{c}\text { Pervasive } \\
(n=901)\end{array}$ \\
\hline $\begin{array}{l}\text { School characteristics } \\
\quad \text { Urban }\end{array}$ & $380(17.0)$ & $249(11.1)$ & $264(11.8)$ & $822(36.8)$ & $521(23.3)$ \\
$\quad$ Rural & $579(32.2)$ & $187(10.4)$ & $205(11.4)$ & $445(24.8)$ & $380(21.2)$ \\
Ethnicity & & & & & $365(27.9)$ \\
$\quad$ African American & $157(12.0)$ & $129(9.9)$ & $137(10.5)$ & $520(39.7)$ & $367(27.4)$ \\
$\quad$ European American & $802(29.4)$ & $307(11.3)$ & $322(12.2)$ & $747(19.7)$ \\
\hline \hline
\end{tabular}

Note: Numbers in parentheses represent percentage of students with each profile within each row.

posure only (recency, $N=469), 2$ years of exposure (chronicity, $N=1,267$ ), and 3 continuous years of exposure (pervasive, $N=$ 901; see descriptive statistics in Table 3).

Consistent with the previously reported findings, a majority of students at urban sites experienced at least 2 years of exposure to high-aggression classrooms $(60 \%)$. In contrast, approximately a third of the students at the rural site $(32 \%)$ experienced no exposure to high-aggression classrooms in the first three grades. Parallel to these findings, African American students in the sample, who were disproportionately represented at the urban sites, were more likely than the European American students in the sample to experience multiple years of exposure to highaggression classrooms (68 vs. $47 \%$, respectively). Approximately a quarter of children from both groups were exposed to an aggressive classroom context once during their first 3 years of elementary school.

Next, univariate general linear modeling procedures were conducted, predicting the aggressive behavior outcomes of children in the third grade by their different profiles of exposure to high-aggression classrooms in Grades $1-3$, while controlling for the effects of school context (size and student poverty), gender, and the student's levels of aggression in kindergarten. Aggressive behavior is a relatively stable characteristic and the linkage between early onset of aggression and later aggressive behavior problems has been well documented (Broidy et al., 2003; Patterson, Capaldi, \& Bank, 1991). Research has also shown consid- erable evidence of gender differences in child aggression, with boys displaying greater rates of conduct problems than girls in elementary school (Crick \& Zahn-Waxler, 2003), and also receiving more socialization support from peers for school aggression (Stormshak et al., 1999). Hence, initial levels of aggressive behavior and gender were controlled for in analyses predicting aggressive outcomes. Recognizing the ways in which rural/urban location, ethnicity, and student exposure to high-aggression classrooms were confounded in the sample, the impact of the different exposure patterns was examined separately for three demographic groups: urban African American students, urban European American students, and rural European American students. The results are shown in Table 4.

Significant main effects on third-grade student aggression were found for the different profiles of exposure to aggressive classrooms for urban African Americans, $F(8,1160)=$ 27.51, $p<.001$, urban European Americans, $F(4,740)=22.59, p<.001$, and rural European Americans, $F(4,1691)=53.66, p<$ .001. Post hoc comparisons using the Tukey test revealed that, across the demographic groups, children exposed to 3 consecutive years of aggressive classrooms had third-grade aggressive-disruptive scores that were significantly higher than children in any other group. Children with a recent or chronic exposure to high-aggression classrooms also showed elevated teacher-rated aggressive-disruptive scores relative to children with a single exposure in Grade 1 or no exposure. No evidence 
Table 4. Analysis of covariance of exposure profiles on child aggression at Grade 3

\begin{tabular}{|c|c|c|c|c|c|c|c|c|c|c|c|}
\hline & \multicolumn{2}{|c|}{ Never } & \multicolumn{2}{|c|}{ Primacy } & \multicolumn{2}{|c|}{ Recency } & \multicolumn{2}{|c|}{ Chronicity } & \multicolumn{2}{|c|}{ Pervasive } & \multirow[b]{2}{*}{$F$} \\
\hline & $M$ & $S D$ & $M$ & $S D$ & $M$ & $S D$ & $M$ & $S D$ & $M$ & $S D$ & \\
\hline Urban African & & & & & & & & & & & \\
\hline $\begin{array}{l}\text { American } \\
\text { Urban European }\end{array}$ & 0.63 & $0.66_{\mathrm{c}}$ & 0.77 & $0.76_{c}$ & 1.25 & $0.88_{b}$ & 1.34 & $1.05 \mathrm{~b}$ & 1.71 & $1.11_{\mathrm{a}}$ & $27.51^{* * *}$ \\
\hline $\begin{array}{c}\text { American } \\
\text { Rural European }\end{array}$ & 0.49 & $0.50_{\mathrm{c}}$ & 0.50 & $0.50_{c}$ & 0.86 & $0.88_{b}$ & 1.00 & $0.91_{\mathrm{b}}$ & 1.35 & $1.14_{\mathrm{a}}$ & $22.59 * * *$ \\
\hline American & 0.51 & $0.60_{c}$ & 0.56 & $0.64_{c}$ & 1.09 & $0.90_{\mathrm{ab}}$ & 0.97 & $0.96 \mathrm{~b}$ & 1.25 & $0.97 \mathrm{a}$ & $53.66 * * *$ \\
\hline
\end{tabular}

Note: Mean scores in the same row that share subscripts do not differ at $p<.05$ using a Tukey's comparison. Covariates include kindergarten teacher-rated behavior scores, gender, school size, and school poverty.

$* * * p<.001$.

emerged linking primacy exposure alone to elevated aggressive outcomes in Grade 3.

\section{Child and school demographics,} high-aggression classrooms, and child behavioral outcomes

Next, SAS PROC MIXED procedures (Singer, 1998) were applied to examine the concurrent effects of child and school demographics and aggressive classroom exposure on children's behavior outcomes in Grade 3. Separate models were estimated for the three demographic groups (urban African American, urban European American, and rural European American students). Third-grade classrooms were treated as a level-2 nesting variable, included to adjust the standard error to control for the dependencies associated with the shared contexts in which outcomes were assessed. These analyses thus assessed the contributions of two individual-level variables (child aggression in kindergarten and gender); two school context variables (school size and poverty); and the level of classroom aggression in Grades 1, 2, and 3 (entered as continuous variables). Results are shown in Table 5.

For all three groups, kindergarten aggression and male gender made significant contributions predicting third-grade aggression. The impact of school context variables depended on location. School size predicted child aggression only for the urban African American children, and school poverty predicted child aggression for the urban (African American and European) children, but not the rural students.
In terms of exposure to classroom aggression, the same pattern of findings emerged for all three groups, with the mean level of classmate aggression at each grade level (Grades 1-3) making unique contributions to the prediction of student third-grade aggression. These findings lend further support to a cumulative model of impact and further suggest that the level of classroom aggression to which children are exposed acts as a continuous variable and has a unique influence associated with each year of exposure.

\section{Discussion}

The present study investigated the demographic distribution and impact of exposure to high-aggression classrooms on the development of child aggression in elementary school. Of particular importance was uncovering the effects of different patterns of exposure to classrooms with high levels of student aggression on individual children's rates of aggression in school over time. Overall, the study found that children's exposure to aggressive classroom contexts during their first 3 years of elementary school is an important factor contributing to the behavioral development of children in that setting.

\section{Demographics associated with exposure to high-aggression classrooms}

The study also yielded some important findings regarding associations among school and child demographics and risk of exposure to 
Table 5. Mixed models predicting Grade 3 aggression for geographic location and child ethnicity

\begin{tabular}{lccc}
\hline \multicolumn{1}{c}{ Standardized Predictors } & Estimate & $S E B$ & $t$ Value \\
\hline Urban African American students & & & \\
Intercept & .016 & .066 & 0.25 \\
K. aggression & .435 & .024 & $17.88^{* * *}$ \\
Gender & .251 & .036 & $6.93^{* * *}$ \\
School size & .086 & .039 & $2.22^{*}$ \\
School poverty & .093 & .044 & $2.13^{*}$ \\
GR1 class & .108 & .044 & $2.49^{* * *}$ \\
GR2 class & .456 & .049 & $9.37^{* * *}$ \\
GR3 class & .240 & .036 & $6.69^{* * *}$ \\
Urban European American students & & & \\
Intercept & -.184 & .090 & $-2.04 *$ \\
K. aggression & .398 & .030 & $13.25^{* * *}$ \\
Gender & .246 & .057 & $4.30^{* * *}$ \\
School size & .045 & .060 & 0.74 \\
School poverty & .199 & .063 & $3.17^{* *}$ \\
GR1 class & .316 & .052 & $6.13^{* * *}$ \\
GR2 class & .359 & .052 & $6.96^{* * *}$ \\
GR3 class & .161 & .040 & $4.07^{* * *}$ \\
Rural European American students & & & \\
Intercept & -.182 & .127 & -1.43 \\
K. aggression & .258 & .026 & $9.79^{* * *}$ \\
Gender & .255 & .057 & $4.45^{* * *}$ \\
School size & .037 & .056 & 0.66 \\
School poverty & .030 & .081 & 0.38 \\
GR1 class & .299 & .047 & $6.42^{* * *}$ \\
GR2 class & .412 & .045 & $9.17^{* * *}$ \\
GR3 class & .276 & .040 & $6.69 * * *$ \\
\hline \hline
\end{tabular}

Note: K. aggression, child aggression in kindergarten; GR1 class, first grade mean classroom aggression levels; GR2 class, second grade mean classroom aggression levels; GR3 class, third grade mean classroom aggression levels.

$* p<.05 . * * p<.01 . * * * p<.001$.

high-aggression classrooms. As predicted, large urban schools serving many economically disadvantaged children were characterized by a preponderance of classrooms with high rates of student aggression. This finding is consistent with prior research revealing elevated rates of student aggression in schools located in impoverished, risky urban areas (Colder et al., 2000; DuRant et al., 1994; Guerra et al., 1995; Howley et al., 2000). Children living in highpoverty, urban areas are exposed to higher levels of violence and antisocial behavior in their community settings, and correspondingly, are more likely to show elevated levels of aggressive behavior at school than children living in safer neighborhoods (McLoyd, 1998), perhaps reflecting their strategic use of aggres- sion to contend with a host of environmental stressors that they encounter inside and outside of their schools. The consequence apparent in the findings of this study is that children attending schools in economically disadvantaged and high-crime neighborhoods are particularly likely to experience school classrooms where aggressive behavior is common among classmates.

Placement in risky school and classroom environments occurred more often for African American than for European American children, due primarily to the demographics of their schools and neighborhoods. That is, by virtue of their centralized urban location, the vast majority of African American children in the sample lived in communities and 
attended schools characterized by high rates of poverty and associated neighborhood risks. This buttresses arguments made by a number of researchers (Garcia Coll et al., 1996; Howley et al., 2000; McLoyd, 1998) that ethnic minority children are at elevated risk for difficulties across multiple domains in the school setting, not because of their ethnicity per se, but due to the fact that they are more likely than other groups of children to be geographically concentrated in impoverished, risky neighborhoods.

Interestingly, however, even when school size, location, and student economic disadvantage were entered first into a regression, child ethnicity still contributed significant, albeit small additional variance to the prediction of aggressive classroom exposure. This finding raises the possibility that tracking within schools further increases the risk that African American children will be exposed to aggressive classroom environments.

Although the present study focused on a selected group of urban schools in high-crime neighborhoods, a large number of American students attend similar schools. For example, recent statistics published by the US Department of Education document that, in the 100 largest public school districts in the United States, $68 \%$ of the students are ethnic minority students and 53\% qualify for free/reduced lunch (National Center for Education Statistics, 2001). These statistics, along with the results of this study on the demographic characteristics of children at risk for exposure to high-aggression classrooms, underscore the importance that researchers have given to better understanding the influence of school context and ethnicity on child behavioral development (Garcia Coll et al., 1996; Hanish \& Guerra, 2000).

\section{Patterns of exposure to high-aggression classrooms}

A central focus of the present study was to examine the degree to which the developmental timing or length of exposure to aggressive classroom contexts would influence the development of aggressive behavior problems in children. Researchers have recognized that en- trance into the first grade is an important developmental juncture for children, and that negative classroom experiences during this first-grade year can increase children's risk for long-term behavioral problems in the school setting (Kellam et al., 1998; Perry \& Weinstein, 1998). Although not studied directly in previous studies, there was also reason to believe that alternative models of classroom influence, such as those based on more recent or chronic temporal patterns of children's exposure to high-aggression classrooms, might also affect the development of child aggressive behavior in school.

The present study found mixed results regarding the effects of primacy exposure to high-aggression classrooms. When primacy effects were separated from the effects of recent and chronic exposure, as part of general linear modeling procedures, a single year of exposure in first grade did not increase aggression for any of the three groups of children studied (African American urban, European American urban, or European American rural children). This was an unexpected result and one that appeared consistent with a developmental model postulated by Belsky and MacKinnon (1994) in which early school adjustment problems are considered transitory, diminishing when followed by subsequent positive school experiences and corrective socialization experiences. However, findings from the mixed models procedures used in the current study provide some support to previous research on the "priming" effect of early behavioral setbacks in school and their long-term consequences for children (Alexander et al., 1993; Hamre \& Pianta, 2001; Kellam et al., 1998). Results showed that exposure to aggressive classrooms during the first grade did contribute to third-grade aggression scores, even after considering exposure during the second and third grades. This was consistent across the geographic location of the participating schools and ethnicity of the participants. Taken together, findings suggest that, although the association between aggressive classrooms in Grade 1 and long-term behavior problems may have to do with a special priming effect of first-grade classroom environments, it may have more to do with the likelihood that chil- 
dren who experience highly aggressive firstgrade classrooms are likely to also experience aggressive classrooms in their later school years. Indeed, in the present sample, the likelihood of being placed in a high-aggression classroom across Grades 1-2 was $r=.25(p<$ $.001)$ and across Grades 2-3 it was $r=.35$ $(p<.001)$.

A single year of exposure to high-aggression classrooms was consistently associated with elevated third-grade aggressive behavior (compared with no exposure) only when the exposure was recent, in the same year as the assessment of child outcomes. Hence, even 1 year of exposure may have a negative impact on child aggression, due possibly to peer contagion and social learning (peer modeling, norm setting, and reinforcement) supporting aggressive behaviors in those classrooms (Dishion et al., 1999) or due to a reaction to the stress engendered by facing a hostile environment during the year (DeRosier et al., 1994). Strong evidence also emerged to support the hypothesis that exposure to highaggression classrooms has cumulative effects on child behavioral adjustment. For children in the urban public schools, those with 3 years of exposure to aggressive classrooms had significantly higher third-grade aggression scores than those exposed to 2 years, which in turn, were significantly higher than the aggression scores of those who were not exposed to highaggression classrooms. The differences were quite marked, with the average third-grade aggression score of children experiencing multiple years of exposure elevated 1-2 SD above the average third-grade aggression score of children at the same sites who experienced no exposure to aggressive classrooms.

In addition, in the multilevel models, the level of classroom aggression to which a child was exposed each year in Grades 1, 2, and 3, contributed significant unique variance in predicting aggressive behavioral outcomes in third grade. Previous research suggests that teachers and peers can contribute to the socialization of aggressive behaviors in the school setting, by the degree to which they model aggressive responding, reinforce aggressive behaviors, or behave in ways that elicit or provoke child aggressive responding (Coie \&
Dodge, 1998; Farmer, 2000; Hamre \& Pianta, 2001). In high-aggression classrooms, children are likely to be exposed to higher levels of peer modeling, provocation, and reinforcement (Dishion et al., 1999), as well as to peer norms that condone aggression (Henry et al., 2000; Stormshak et al., 1999). Teachers struggling to maintain order in these classrooms may more often make use of coercive control tactics that may increase aggressive reactivity and decrease student school engagement fostered by more positive teacherstudent relationships. All of these factors may combine to account for the socializing impact of classmate aggression on student aggressive outcomes.

It was hypothesized that student risk for exposure to high-aggression classrooms would be elevated for students attending large, urban, and economically disadvantaged schools, but that classroom contexts would contribute significantly to the prediction of child aggression for these students, beyond the influence of these school demographics. Results of the mixed statistical analyses indicated that individual child aggression levels at the point of school entry were the strongest predictor of child aggression 3 years later, and that gender also made a significant contribution to this child outcome. School characteristics (size and proportion of students who qualified for free/ reduced lunch) made only negligible contributions to this prediction for European American students. With baseline child aggression, gender, and these school demographics in the model, children's exposure to high-aggression classrooms accounted for a sizable and significant amount of variance in child third-grade aggressive outcomes for all three groups of children studied.

These findings suggest that the impact of student poverty and school size on student behavior is more distal than the impact of the classroom context, and that these more general school demographics have less influence on child behavioral adjustment than the more proximal socialization influences exerted by teachers and peers in the classroom context. The reliability of the findings regarding classroom influence across the three groups studied suggests that it is a robust contribution 
that can be identified even when the distribution of classroom contexts is attenuated by splitting the sample into demographic groups with differing risk rates for exposure. The cumulative effects evident in the multilevel models indicate that exposure to aggressive classrooms may add to the risk of early aggressive behavior problems, suggesting that the prognosis for resilient recovery from early behavior problems may be particularly poor for at-risk children entering schools with a high likelihood of chronic exposure to poorly managed classrooms with a high concentration of aggressive peers.

\section{Limitations and Future Directions}

This study did not include any direct observational measures of classroom peer interaction processes or teacher management processes, making it difficult to isolate the mechanisms of action that account for the apparent impact of exposure to aggressive classrooms on child behavioral adjustment. In addition, although exposure to neighborhood violence and victimization was viewed in this study as a key determinant for child aggressiveness, the study did not contain any direct assessment of this risk factor. The associations between children's exposure to high rates of community violence and their behavior adjustment in school, especially for children attending schools in lowincome, urban neighborhoods have been well documented (Colder et al., 2000; DuRant et al., 1994; Guerra et al., 1995). It is possible that the problems associated with children's encounters with violence in their neighborhoods might have had a substantial influence on their rates of aggression in the school settings. Furthermore, the authors acknowledge the possibility that other school-level variables not investigated here might have had some effect on the student aggression levels studied. Research indicates that a significant amount of school-related aggression and victimization occurs in situations with peers outside of the classroom and where there is limited adult supervision, such as playgrounds, lunchrooms, and in hallways (Astor \& Meyer, 2001; Leff, Costigan, \& Power, 2004; Olweus, 1993). Hence, future research is needed to determine whether exposure to aggression in these school contexts contributes in additional ways to the socialization of aggression.

From a methodological standpoint, classroom aggression and student aggression were both assessed with teacher ratings in this study. The possibility that teacher-rating biases accounted for (or contributed to) the findings exists primarily for analyses that included thirdgrade classroom environments and third-grade child outcomes, which shared a rating source (the third-grade teachers). The removal of individual aggression scores in the calculation of classroom aggression scores for each child and the use of PROC MIXED procedures, which take into account third-grade classroom nesting, provided some protection against the risk that findings reflect teacher-rating biases. In addition, the pattern of results appeared quite robust across analyses that include classroom aggression ratings from first- and second-grade teachers that involved ratings independent of the third-grade teacher ratings of child outcomes.

Despite these limitations, results of this study have important implications for future research on the development of childhood aggression. Undoubtedly, more research efforts should be aimed at advancing what is currently known about the influence of children's exposure to poorly managed, aggressive classrooms during their early elementary school years on their development of aggressive behavior problems in school. An important aspect of this research should be on elucidating the underlying developmental processes by which children are shaped by teachers and peers to display elevated levels of acting out behaviors in the classroom. On a broader scale, research should build upon the discoveries made in this and other studies (Barth et al., 2004; Kellam et al., 1998) regarding the impact of high-aggression classrooms on the course of child levels of aggression across time and different grade levels. The present study furthers findings by Kellam et al. (1998) by suggesting that, in addition to the impact of early exposure to aggressive classrooms on long-term outcomes, there are also other experiences in the intervening years that play critical roles in affecting the stability of ag- 
gressive behavior problems for children. This study documents for the first time the impact of recent and chronic negative classroom experiences on the behavioral development of children during their early school years. However, the model used here was an additive one. Future efforts in this area that make use of broader transactional models that consider the complex and reciprocal interplay between individual, classroom, school contextual, and perhaps sociocultural factors not studied here (e.g., academic tracking, school policies, or discriminatory practices) that are linked to developmental risks in children would enhance our understanding of school and classroom influences on child aggression.

Findings from the present study also have important implications for preventive interventions. They suggest that we continue to explore and adopt ecological interventions for the classroom. That is, interventions for school aggression need to assess and target classroom environments directly, with strategies focused on enhancing teacher management practices and promoting positive teacherchild relations (Conduct Problems Prevention Research Group, 1999; Webster-Stratton, Reid, \& Hammond, 2004). Simultaneously directing efforts to foster positive peer communities in schools and to promote nonaggressive, prosocial norms in classrooms (and at wider school levels) would be worthy directions for prevention work. The current findings shed light on a population of children at great risk for exposure to high-aggression classrooms during their early school years and its consequences on their behavioral development: low-income urban African American children. These results should encourage researchers, service providers, and education policy makers alike to consider disparities in the academic experiences and opportunity structures afforded children in schools, with particular attention given to children in urban public school districts with the highest rates of economic disadvantage, who disproportionately tend to be children of color. On the basis of present research findings, policies that support smaller class sizes in urban public schools, promote the training and retention of qualified teachers, and increasing comprehensive school-based strategies to address children's adaptation difficulties early on and across their elementary school years are worthy directions for future pursuit. Clearly, further longitudinal work is needed to more fully explore and understand the impact of classroom social ecologies on children's behavioral development and school adjustment during elementary school. Overall, broader conceptual and evaluation frameworks are needed in preventive interventions, to better assess the impact of such interventions on the classroom ecology and school social context, as well as on high-risk children who may be identified targets for intervention.

\section{References}

Alexander, K. L., Entwisle, D. R., \& Dauber, S. L. (1993). First-grade classroom behavior: Its short- and longterm consequences for school performance. Child Development, 64, 801-814.

Asarnow, J. R. (1983). Children with peer adjustment problems: Sequential and nonsequential analyses of school behaviors. Journal of Consulting and Clinical Psychology, 51, 709-717.

Astor, R. A., \& Meyer, H. A. (2001). The conceptualization of violence-prone school subcontexts: Is the sum of the parts greater than the whole? Urban Education, 36, 374-399.

Barth, J. M., Dunlap, S. T., Dane, H., Lochman, J. E., \& Wells, K. C. (2004). Classroom environment influences on aggression, peer relations, and academic focus. Journal of School Psychology, 42, 115-133.

Battistich, V., Solomon, D., Kim, D., Watson, M., \& Schaps, E. (1995). Schools as communities, poverty levels of student populations, and student attitudes, motives, and performance: A multilevel analysis. American Educational Research Journal, 32, 627-658.

Belsky, J., \& MacKinnon, C. (1994). Transition to school: Developmental trajectories and school experiences. Early Education and Development, 5, 106-119.

Boivin, M., Dodge, K. A., \& Coie, J. D. (1995). Individualgroup behavioral similarity and peer status in experimental play groups of boys: The social misfit revisited. Journal of Personality and Social Psychology, 69, 269-279.

Broidy, L. M., Nagin, D. S., Trembley, R. E., Bates, J. E., Brame, B., Dodge, K. A., et al. (2003). Developmental trajectories of childhood disruptive behaviors and adolescent delinquency: A six-site, cross-national study. Developmental Psychology, 39, 222-245.

Brophy, J. E. (1996). Teaching problem students. New York: Guilford Press.

Coie, J. D., \& Dodge, K. A. (1998). Aggression and antisocial behavior. In W. Damon (Ser. Ed.) \& N. Eisen- 
berg (Ed.), Handbook of child psychology: Vol. 3. Social, emotional, and personality development (pp. 779-862). New York: Wiley.

Colder, C. R., Mott, J. A., Flay, B. R., \& Levy, S. (2000). The relationship between neighborhood danger and childhood aggression: A test of mediational mechanisms. American Journal of Community Psychology, $28,83-103$.

Conduct Problems Prevention Research Group. (1992). A developmental and clinical model for the prevention of conduct disorders: The FAST Track program. Development and Psychopathology, 4, 509-575.

Conduct Problems Prevention Research Group. (1999). Initial impact of the fast track prevention trail for conduct problems: II. Classroom effects. Journal of Consulting and Clinical Psychology, 67, 648-657.

Crick, N. R., \& Zahn-Waxler, C. (2003). The development of psychopathology in females and males: Current progress and future challenges. Development and Psychopathology, 15, 719-742.

DeRosier, M. E., Kupersmidt, J. B., \& Patterson, C. J. (1994). Children's academic and behavioral adjustment as a function of the chronicity and proximity of peer rejection. Child Development, 65, 1799-1813.

Dishion, T. J., McCord, J., \& Poulin, F. (1999). When interventions harm: Peer groups and problem behavior. American Psychologists, 54, 755-764.

Dishion, T. J., Spracklen, K. M., Andrews, D. W., \& Patterson, G. R. (1996). Deviancy training in male adolescent friendships. Behavior Therapy, 27, 373-390.

Dohrenwend, B. S., \& Dohrenwend, B. P. (1984). Life stress and illness: Formulation of the issues. In B. S. Dohrenwend \& B. P. Dohrenwend (Eds.), Stressful life events and their contexts: Vol. 2. Series in psychosocial epidemiology (pp. 1-27). Rutgers, NJ: Rutgers University Press.

DuRant, R. H., Pendergrast, R. A., \& Cadenhead, C. (1994). Exposure to violence and victimization and fighting behavior by urban Black adolescents. Journal of Adolescent Health, 15, 311-318.

Farmer, T. W. (2000). The social dynamics of aggressive and disruptive behavior in school: Implications for behavior consultation. Journal of Educational and Psychological Consultation, 11, 299-321.

Garcia Coll, C., Lamberty, G., Jenkins, R., McAdoo, H. P., Crnic, K., Wasik, B. H., et al. (1996). An integrative model for the study of developmental competencies in minority children. Child Development, 67, 1891-1914.

Guerra, N. G., Tolan, P. H., Eron, L. D., Huesmann, L. R., \& Van Acker, R. (1995). Stressful events and individual beliefs as correlates of economic disadvantage and aggression among urban children. Journal of Consulting and Clinical Psychology, 63, 518-528.

Hamre, B. K., \& Pianta, R. C. (2001). Early teacher-child relationships and the trajectory of children's school outcomes through eight grade. Child Development, $72,625-638$.

Hanish, L. D., \& Guerra, N. G. (2000). The roles of ethnicity and school context in predicting children's victimization by peers. American Journal of Coтmunity Psychology, 28, 201-223.

Hawkins, J. D., VonCleve, E., \& Catalano, R. F. (1991). Reducing early childhood aggression: Results of a primary prevention program. Journal of the American Academy of Child and Adolescent Psychiatry, 30, 208-217.
Henry, D., Guerra, N., Huesmann, R., Tolan, P., VanAcker, R., \& Eron, L. (2000). Normative influences on aggression in urban elementary school classrooms. American Journal of Community Psychology, 28, 59-81.

Howley, C., Strange, M., \& Bickel, R. (2000). Research about school size and school performance in impoverished communities (ERIC Document Reproduction Service No. ED448968). ERIC Digests. Retrieved from www.ericdigests.org/2001-3/size.htm

Hughes, J. N., Cavell, T. A., \& Jackson, T. (1999). Influence of the teacher-student relationship on childhood conduct problems: A prospective study. Journal of Clinical Child Psychology, 28, 173-184.

Johnson, J. H. (1988). Life events as stressors in childhood and adolescence. Thousand Oaks, CA: Sage.

Kellam, S. G., Ling, X., Merisca, R., Brown, C. H., \& Ialongo, N. (1998). The effect of the level of aggression in the first grade classroom on the course and malleability of aggressive behavior in middle school. Development and Psychopathology, 10, 165-185.

Kellam, S. G., \& Rebok, G. W. (1992). Building developmental and etiological theory through epidemiologically based preventive intervention trials. In J McCord \& R. E. Trembley (Eds.), Preventing antisocial behavior: Interventions from birth to adolescence (pp. 162-195). New York: Guilford Press.

Leff, S., Costigan, T., \& Power, T. (2004). Using participatory research to develop a playground-based prevention program. Journal of School Psychology, 42, $3-21$.

McLoyd, V. C. (1998). Socioeconomic disadvantage and child development. American Psychologist, 53, 185-204.

Miller-Johnson, S., Costanzo, P. R., Coie, J. D., Rose, M. R., Browne, D. C., \& Johnson, C. (2003). Peer social structure and risk-taking behaviors among African American early adolescents. Journal of youth and adolescence, 32, 375-384.

National Center for Education Statistics. (2001). Characteristics of the 100 largest school districts in the United States: 1999-2000. Washington, DC: US Department of Education, Office of Educational Research and Improvement. Retrieved from http://nces.ed.gov/pubs 2001/100_largest/highlights.asp

Olweus, D. (1993). Bullies on the playground: The role of victimization. In C. H. Hart (Ed.), Children on playgrounds: Research perspectives and applications (pp. 85-128). Albany, NY: State University of New York Press.

Patterson, G. R., Capaldi, D., \& Bank, L. (1991). An early starter model for predicting delinquency. In D. J. Pepler \& K. H. Rubin (Eds.), The development and treatment of childhood aggression (pp. 139-168). Hillsdale, NJ: Erlbaum.

Perry, K. E., \& Weinstein, R. S. (1998). The social context of early schooling and children's school adjustment. Educational Psychologists, 33, 177-194.

Rutter, M. (1983). School effects on pupil progress: Research findings and policy implications. Child Development, 54, 1-29.

Singer, J. (1998). Using SAS PROC MIXED to fit multilevel models, hierarchical models, and individual growth models. Journal of Educational and Behavioral Statistics, 24, 323-355.

Stephenson, P., \& Smith, D. (1989). Bullying in the junior school. In D. Tattum \& D. Lane (Eds.), Bullying in schools (pp. 45-59). Stoke on Trent: Trentham. 
Stormshak, E. A., Bierman, K. L., Brushi, C., Dodge, K. A., Coie, J. D., \& The Conduct Problems Prevention Research Group (1999). The relation between behavior problems and peer preference in different classroom contexts. Child Development, 70, 169-182.

Tversky, A. (1977). Features of similarity. Psychological Review, 84, 327-354.

Webster-Stratton, C., Reid, M. J., \& Hammond, M. (2004). Treating children with early-onset conduct problems: Intervention outcomes for parent, child, and teacher training. Journal of Clinical child and Adolescent Psychology, 33, 105-124.

Werthamer-Larsson, L., Kellam, S. G., \& Wheeler, L. (1991). Effect of first-grade classroom environment on shy behavior, aggressive behavior, and concentration problems. American Journal of Community Psychology, 19, 585-602.

Wright, J. C., Giammarino, M., \& Parad, H. W. (1986). Social status in small groups: Individual-group similarity and the social "misfit." Journal of Personality and Social Psychology, 50, 523-536. 